\title{
Examining the Relationship between Gender and Psychological Well-Being
}

\author{
Mohsen Khanbani \\ Department of Psychology, Islamic Azad University, Khorasgan Branch, Isfahan, Iran \\ E-mail: Mirhadi8000@gmail.com
}

\begin{abstract}
Asghar Aghaee
Association Professor, Department of Psychology, Islamic Azad University, Khorasgan Branch, Isfahan, Iran

Mohsen Gol Parvar

Assistant Professor, Department of Psychology, Islamic Azad University, Khorasgan Branch, Isfahan, Iran

Doi:10.5296/jsr.v5i1.5436

URL: http://dx.doi.org/10.5296/jsr.v5i1.5436
\end{abstract}

\begin{abstract}
The purpose of this study was" Examine the relationship between gender and psychological well-being" (Self-acceptance, positive relations with others, autonomy, environmental mastery and personal growth) among married men and women in Isfahan.The research sample included men and women who have been living together for 5 to 10 years.For this purpose, the sample consisted of 231 couples based on a multi-stage sampling selected and studied.The research method was descriptive, causal-comparative. Research tools was Psychological well-being questionnaire Reef (2009).The results showed that there was significant difference between men and women in positive relations with others, environmental mastery and personal growth $(\mathrm{p} \leq 0.01)$. But there was no significant relationship in self-acceptance and Autonomy.
\end{abstract}

Keywords: Psychological Well-being, Women, Men, Iran

\section{Psychological well-being}

It appears that mental health is a relatively broad concept. In the past mental health was considered as a concept of individual, then it was defined as the absence of mental illness. In 1948, the World Health Organization (WHO) defined health in terms of mental health as a complete state of physical, mental, social, and not merely the absence of disease. Where the assessment of health status and physical examination bodies will be quite simple, assessing the psychosocial health is much more difficult .This probably is because of mental health is multidimensional structures that they have not only physical aspects but also have mental aspects (subjective). The mental (subjective) is the internal state which is non-objective and therefore it is difficult to define its quality (Routledge,2005).. Overall, it appears that 
psychological well-being is associated with a range of structures like life satisfaction, happiness ,adjustment ,affect ,morale and subjective well-being.In 1989,Psychological Association of South Africa as defined mental health the circumstances led to the situation that the people in their individual capacities (regardless of age, gender or color) and interact with each other as community members can live high quality in all areas and take advantage of situations where there is a choice to actualize their potential (Routledge,2005.)

\subsection{Different definitions of health and well-being}

- "Well Being " is an integrated method of functioning Which is oriented toward maximizing the potential (Dunn,1961).

- Responsibility for your health means conscious commitment towards your well-being. You choose the positive aspects to obtain virtue and excellence that have effect on four aspects:

- Areas of physical, mental, emotional and spiritual (Adller,1982).

- An active process through which you become aware and choose and hope to healthier and more successful life.

- "Well-being " is an approach that will consider the whole person, not just biological organisms (Hettler,1984).

- Successful ,adaptive and innovative partnership in common.

- wellbeing is the way of life and sense of balance. This sense of balance is the result of balance or coordination with any aspect or dimension of life (Lowdon Davis,Dickie \& Ferguson,1995).

- Well-being or a sense of well-being Health including the ability to live and work effectively with community .

- Well-being is optimization and optimal health and building their capacities and others .

\subsection{Dimentions of Psychological well-being}

1.2.1. Self-acceptance: Greek recommend that we must recognize ourselves. That is, an attempt to apply the correct perception, motivation and sense of self.Self-acceptance is defined as the main feature of mental health (Jahvda), Characteristics of self-actualization (Maslow), Positive action (Rogers).It is a self-assessment includes awareness and acceptance of personal strengths and weaknesse (Ryff \& Singer,2008).Self-acceptance is determined with features like positive thinking to self, recognition of the existence of multiple dimensions self, also, a positive attitude towards its past (Shokri \& et al,2008).

1.2.2. Positive relations with others: All approaches described above are the personal domain as a major feature of a positive life. For example, Jahvda assume" love" as a major component of mental health. while Maslow describes self-actualization as having a strong passion for all creatures and resemble closely with others.

1.2.3. Personal Growth: Of all the aspects of well-being, personal growth is the closest meaning with Aristotle's virtue-oriented because It is clearly related to 
self-actualization.so it involves an ongoing process of developing one's potential (Shokri \& et al,2008).

1.2.4. Purpose in Life: This part of the wellbeing is shaped to a large extent based on the views of existential perspective of Frankle. Logotherapy of Frankle directly related him by helping people to find meaning and purpose in difficulties of life. According to Sartre, the fundamental challenge is the meaning of life is real life. Allport's definition of wellbeing is'having a clear understanding of the purpose of life which including a sense of being guided and having the intention'. Growth theories point to a change in their life goals that are specific to the different periods of life such as, being creative or constructive in midlife and tend to emotional integration in old age Ryff \& Singer,2008).

1.2.5. Tendency towards dominance:Jahvda defines the ability of individual to select or create appropriate environments for his mental conditions as key feature of mental health. Growth theories durin the lif insist on the ability to handle complex environments, especially in middle age and the ability to act and change the world around through physical and mental activities (Shokri \& et al,2008).

\subsection{Health concept}

There are several practical elements, which are associated with the overall health of individuals. Elements such as intelligence, personality, physical structure are generally considered to be the product of genetic composition. Gagne refers to this as the natural abilities. Although these are natural components of the individual but these elements are influenced by the environment of the normal process of growth performance (Gagné, 2004).If you have a lot of physical ability but there is no positive catalysts for the growth of its capabilities into the environment initiative, it is likely that the reduced sense of their health.Similarly, if individual has a genetic background to grow and become strong and healthy person but to live in a nutritionally poor environment Less likely to develop their full potential in terms of physical and mentallf a person has a lively personality and placed in an environment that does not provide the possibility of freshness and vitality to this feature, mental and social health of a person is injured (Lerner \& Steinber,2004). Health is defined as a state of successful performance throughout the life including power in physical functioning, cognitive, social and emotional And the successful integration of these three areas.Successful integration of these three areas leads to a rich and fertile and enjoyable activities(Maslahati,2004).The integration of physical, cognitive and social - emotional function help to Helps the community relations And helps individuals To overcome the environmental problems and psychosocial.

\subsection{Model of psychological well-being of Riff}

Riff model is the most important model the domain of psychological well-being.In this perspective, well-being means attempt to sense of promotion which is manifested in the realization of one's talents and abilities.This model recognizes the psychological well-being as a holistic development process which is spread over a lifetime.Reef and colleagues attempted based on the philosophical foundations (People like Aristotle and Russell) cetermine decent life standards, or so-called "good life".Accordingly, identified six major factors that can be determined to be good or not. self - acceptance, purpose in life, personal 
growth, positive relations with others, environment al mastery,autonomy are constituent components of psychological well-being in Reef Model.He claims that psychological well-being is a critical element of faith which gives a sense of purpose and meaning in life. In addition, he states that specific objectives of life, purposes and intentions and having a sense of direction and orientation all are associated with the feeling( Ryff \& Singer,2008).

\section{Research Method}

This study is a Retrospective / Ex - Post Facto research. The The population included men and women have been living together for 5 to 10 years. The sample size of this study were 462 individuals (231 couples) Which were selected by multistage sampling method. Research tools was Psychological well-being questionnaire Reef (2009). Psychological well-being questionnaire of Reef(1980), which has 18 items and six subscales called self-acceptance, positive realation with other, outonomy, environment mastery, persnoal growth.In the present study, Cronbach's alpha of self-acceptance, positive realation with other, outonomy, environment mastery, persnoal growth is $0.7,0.44,0.63,0.4,0.54$.

\subsection{Main hypothesis}

There is a significant relationship between gender and psychological well-being. The following table presents the Mean and standard deviation of psychological well-being in women and men.

Table1: Mean and standard deviation of psychological well-being in women and men

\begin{tabular}{|c|c|c|c|}
\hline $\begin{array}{c}\text { Dimentions of Psychological } \\
\text { well-being }\end{array}$ & gender & SD & M \\
\hline \multirow{2}{*}{$\begin{array}{c}\text { self - acceptance } \\
\text { positive relations with others }\end{array}$} & Man & $0 / 98$ & $2 / 41$ \\
\cline { 2 - 4 } & Woman & $1 / 2$ & $2 / 35$ \\
\cline { 2 - 4 } & Moman & $0 / 88$ & $2 / 5$ \\
\hline \multirow{2}{*}{ autonomy } & Man & $0 / 9$ & $2 / 11$ \\
\cline { 2 - 4 } & Woman & $1 / 19$ & $2 / 16$ \\
\hline \multirow{2}{*}{ environment al mastery } & Man & $0 / 85$ & $2 / 31$ \\
\cline { 2 - 4 } & Woman & $0 / 76$ & $2 / 1$ \\
\hline \multirow{2}{*}{ personal growth } & Man & $1 / 1$ & $1 / 95$ \\
\cline { 2 - 4 } & Woman & $0 / 85$ & $1 / 59$ \\
\hline
\end{tabular}

The following table presents the results of multivariate analysis of variance (MANOVA) for psychological well-being. 
Table2:Results of multivariate analysis of variance on psychological well-being in women

\begin{tabular}{|c|c|c|c|c|c|c|}
\hline $\begin{array}{c}\text { Dimentions of } \\
\text { Psychological well-being }\end{array}$ & df & $\eta^{2}$ & $\eta$ & sig & F & Mean \\
\hline self - acceptance & 1 & $0 / 027$ & $0 / 16$ & $0 / 52$ & $0 / 4$ & $0 / 49$ \\
\hline $\begin{array}{c}\text { positive relations with } \\
\text { others }\end{array}$ & 1 & $0 / 003$ & $0 / 05$ & $0 / 000$ & $12 / 43$ & $12 / 61$ \\
\hline autonomy & 1 & $0 / 025$ & $0 / 16$ & $0 / 09$ & $2 / 94$ & $3 / 29$ \\
\hline $\begin{array}{c}\text { environment al mastery } \\
\text { personal growth }\end{array}$ & 1 & $0 / 024$ & $0 / 15$ & $0 / 007$ & $7 / 45$ & $4 / 85$ \\
\hline & 1 & $0 / 015$ & $0 / 12$ & $0 / 000$ & $15 / 63$ & $15 / 09$ \\
\hline
\end{tabular}

H1: There is a significant relationship between gender and self-acceptance.

As can be seen in the table $2\left(\eta=0.16, \eta^{2}=0.027\right.$, Means that there is $2.7 \%$ shared variance between gender and self-acceptance, $\mathrm{P}>0.05$ ) there is no significant relationship between self - acceptance and gender.Thus, the first sub-hypothesis is not confirmed.

$\mathrm{H} 2$ : There is a significant relationship between gender and positive relationships with others.

As can be seen in the table $2\left(\eta=0.05, \eta^{2}=0.003\right.$, Means that there is $0.3 \%$ shared variance between gender and positive relationships with others, $\mathrm{P}<0.05$ ) there is relationship beetwen gender and positive relationships with others. Thus, the second hypothesis is confirmed.

H3: There is a significant relationship between gender and autonomy.

As can be seen in the table $2 \quad\left(\eta=0.16, \eta^{2}=0.025\right.$, Means that there is $2.7 \%$ shared variance between gender and self-acceptance, $\mathrm{P}>0.05$ ) there is no significant relationship between autonomy and gender.Thus, the third sub-hypothesis is not confirmed.

H4: There is a significant relationship between gender and environment al mastery.

As can be seen in the table $2\left(\eta=0.15, \eta^{2}=0.024\right.$, Means that there is $0.3 \%$ shared variance between gender and positive relationships with others, $\mathrm{P}<0.05)$ there is relationship beetwen gender and environment al mastery. Thus, the fourth hypothesis is confirmed.

H5: There is a significant relationship between gender and personal growth.

As can be seen in the table $2\left(\eta=0.12, \eta^{2}=0.015\right.$, Means that there is $0.015 \%$ shared variance between gender and positive relationships with others, $\mathrm{P}<0.05)$ there is relationship beetwen gender and personal growth. Thus, the Fifth hypothesis is confirmed.

\section{Summary and Concluding Remarks}

The research findings can be said that due to the restrictions exist in society and families to connect women with others, especially with the opposite sex, It makes women consider their concerns in relations with others and avoid of many situations and people. Therefore, the effect of these factors makes the relationship is in trouble,self-Presentation is not possible in many situations and can not to enter some social.This is especially problematic when women communicate freely in relations with others, especially with the opposite sex, and show a sincere and friendly manner that led to abuse and create a problem for them.On the other hand, patriarchal thinking and traditional beliefs in some cultures and families are an obstacle to growth and expression abilities, talents and capabilities of women.They are forced to accept 


\section{Macrothink}

Journal of Sociological Research

ISSN 1948-5468

2014, Vol. 5, No.1

Restraints and ignore the many interests and developmental needs and opportunities Despite the improved conditions, as well as continuing education or job , Sexism and patriarchal notions is an obstacle to growth. On the other hand, the results show that there is no significant difference between men and women in their self-acceptance which is due to the change in the condition of women in society in recent years and has created business opportunities for women in education and employment and created some rules in favor of women an further support comes from women.This has led to the development of self-confidence and independence in women.

\section{Corresponding Author}

Mohsen Khanbani, Department of Psychology, Islamic Azad University, Khorasgan Branch of Isfahan, Iran Mirhadi8000@gmail.com

\section{References}

Adler, M.J. (1982). The Paideia Proposal. New York: MacMillan Publishing Co.

Dunn, Halbert L. (1961), High Level Wellness. Arlington, VA: R.W. Beatty, Ltd.

Eugenics Watch. (n.d.): Retrieved on 1 August 2004 from http://www.africa2000.com /ENDX/ aenames.htm

Gagné, F. (2004). Transforming gifts into talents, the DMGT as a developmental theory. High ability studies, 15 (2), 119-147.

Hettler, W. (1984). Wellness: Encouraging a lifetime pursuitof excellence. Health Values: Achieving High Level Wellness, 8,13-17.

Lerner R, Steinberg L., (2004). The scientific study of adolescence: Past, present, and future. In: Lerner R, Steinberg L, editors. Handbook of adolescent psychology. 2. New York: Wiley, $1-12$.

Maslahati,H.(2003). Marriage and Marriage Therapy. second edition .tehran:releses Alborz.p.12.

Routledge, L A.(2005).Substance and Psychological Well-Being of South African Adolescentse in anUrvan context. MA Clinical Psychology.Faculty of Humanities in the Department of Psychology at the University of Pretoria.

Ryff, CD. Singer, B H.(2008).Know they self and become what you are: A Eudaimonic Approach to Psychological Well-Being.Journal of Happiness Studies,9:13-39

Shokri, A., kadivar, P., Farzad, V., Daneshvar por, Z., Dastjerdi, R., Paeezi, M., (2008). Factor structure of the Farsi version, Iranian Journal of Psychiatry and Clinical Psychology, 2(14), 152-161. 